\title{
Bacteria Causing Canine and Feline Hemorrhagic Gastroenteritis and Histopathological Studies in Experimentally Infected Dogs and Cats with Salmonella and Escherichia coli Strains
}

\begin{abstract}
Enany, Mohamed El Sayed ${ }^{1}$; Wahdan Ali';
Marwa El-Sayed Abo Hashem ${ }^{1}$; Amina Ali Dessouki²;

Wafaa M Hassan ${ }^{3}$ and Marwa El-Metwaly El-Metwaly ${ }^{4}$

${ }^{1}$ Bacteriology, Immunology and Mycology Department, Faculty of Veterinary Medicine, Suez Canal University, Ismailia Governorate, Egypt. ${ }^{2}$ Department of Pathology, Faculty of Veterinary Medicine, Suez Canal University, Ismailia Governorate, Egypt. ${ }^{3}$ Chief research, Technicalmanager of Microbiology, Reference lab. of Quality Control on Poultry Production, Animal Health Research Institute. ${ }^{4}$ Department of Zoonotic Diseases, Veterinary Medicine Directorate, Damietta, Egypt.

Corresponding author: mmghobary21@gmail.com,
\end{abstract}

\begin{abstract}
:
Hemorrhagic gastroenteritis is a potentially fatal disease especially in untreated animals. Total samples of 202 rectal swabs collected from dogs and cats were subjected to bacteriological examination. One hundred four bacterial isolates were identified from the total 202 examined samples. The identified bacterial isolates were E. coli (46; $44.23 \%)$, Proteus species (22; 21.15\%), Klebsiella species (9; 8.65\%), C. perfringens (5; 4.80\%), Enterobacter species (4; $3.84 \%)$, Pseudomonas aeruginosa (4; 3.84\%), Salmonella species $(3 ; 2.88 \%)$, Shigella species $(3 ; 2.88 \%)$; Citrobacter species $(2 ; 1.92 \%)$, Providencia rettgeri $(2 ; 1.92 \%)$, Serratia liquefaciens $(1 ; 0.96 \%)$, Hafnia species $(1 ; 0.96 \%), C$. bifermentans $(1 ; 0.96 \%), C$. putrefaciens $(1 ; 0.96 \%)$. Serological identification for some E. coli isolates revealed that EHEC strains represent (12/26, 46.15\%), EPEC (9/26, $34.61 \%)$, ETEC (4/26, 15.38\%) and EIEC (1/26, 3.85\%). Serotyping of Salmonella isolates detected $S$. Typhymurium, $S$. Heidelberg and $S$. Infantis. In case of canine E. coli isolates, resistance was recorded against amoxicillin/clavulanic acid, cephalexin, ceftriaxone, tetracycline, erythromycin and trimethoprim/sulphamethoxazole. Moderate resistance was recorded among feline $E$. coli isolates to
\end{abstract}


amoxicillin/clavulanic acid, tetracycline and trimethoprim/ sulphamethoxazole. Salmonella isolates were highly resistant to amoxicillin/clavulanic acid, cephalexin, erythromycin, tetracycline and trimethoprim/sulphamethoxazole. In experimentally infected puppies with $S$. Typhymurium, histopathological examination showed necrosis in the tips of the villi and leukocytic infiltration in the submucosa of the jejunum, degeneration and fibrosis of the liver. In experimental salmonellosis in cats, histopathological examination showed coagulative necrosis in the tips of the villi of the jejunum and multifocal necrosis in the liver. In experimental E. coli infection in cats, histopathological examination showed ulceration and necrosis of the small intestine. The liver showed congestion of the blood vessels and fibrosis around the hepatic areas.

Keywords: Hemorrhagic Gastroenteritis, histopathological studies, experimental infection, Salmonella, Escherichia coli, dogs and cats.

\section{Introduction}

Hemorrhagic

Gastroenteritis (HGE) is a potentially life-threatening disease of dogs, characterized by sudden onset of bloody, watery diarrhea and vomiting (Unterer et al., 2011). If it is left untreated, the dog can be affected by shock then die. Understanding the enteritis pathophysiology is limited, because the microflora of the intestine in dogs and cats is complicated and incompletely understood organisms (Weese, 2011). Many bacteria causing HGE have a potential hazard to public health. Pets and domestic animals constitute natural reservoir for Attaching and effacing $E$. coli (AEEC) strains (Krause et al., 2005). Dogs and horses act as potential reservoir for EHEC O157: $\mathrm{H} 7$ in human (Trevena et al., 1996). Canine Salmonella shedding represents a potential public health hazard (Leahy et al., 2016). Dogs and cats represent potential source for the antimicrobial resistance spread due to their close contact with human and the massive use of antimicrobial drugs in dogs and cats' treatment (Weese, 2011). The community-related Enterobacteriaceae have extensive resistance attributed to the extended spectrum $\beta$ lactamases (Pitout, 2013). The study aimed to isolate bacteria causing HGE in dogs and cats, serological studies for some bacterial isolates, antimicrobial sensitivity test for some E. coli 
and Salmonella, $P$. mirabilis and $K$. pneumoniae isolates, experimental study of salmonellos is in dogs and cats, experimental study of E. coli infection in cats, and histopathological studies for some experimentally infected cases.

\section{Materials and methods}

\section{Samples}

Two hundred and two rectal swabs were collected from housed dogs and cats (143 of dogs and 59 of cats) that suffered from bloody diarrhea and suspected to have hemorrhagic gastroenteritis. Samples were collected from private pet clinics and Governmental Pet Animals Units in Damietta and Dakahlia Governorates, Egypt during the period from February 2017 till April 2020, then subjected to bacteriological examination.

\section{Bacte riological examination}

2.1. Isolation and identification of Enterobacteriaceae

For E. coli and Klebsiella isolation, inoculation of fecal swabs was made into buffered peptone water ( $\mathrm{Lab} \mathrm{M})$, incubation at $37^{\circ} \mathrm{C}$ for $24 \mathrm{~h}$, then streaking of inoculum was made onto the surface of MacConkey's agar (Oxoid) and incubation at $37^{\circ} \mathrm{C}$ for $24 \mathrm{~h}$. The colonies suspected to be lactose fermenter were streaked onto EMB (eosin methylene blue) agar plates (HiMedia). For Salmonella isolation, pre-enrichment of samples was made by inoculation into RappaportVassiliadis broth (Lab M), incubation at $41.5^{\circ} \mathrm{C}$ for $24 \mathrm{~h}$, then plating on XLD (Xylose Lysine Deoxycholate) agar (HiMedia), and incubation at $37^{\circ} \mathrm{C}$ for $24 \mathrm{~h}$. Identification of Klebsiella isolates was done morphologically on EMB agar. For Klebsiella isolates, detection of mucoviscosity was done according to Shon et al. (2013) by inoculation of a loopful taken from the suspected culture on nutrient agar (Lab M). Any produced viscous string longer than $5 \mathrm{~mm}$ was considered positive result and the isolate was identified as HVKP (hypermucoviscous $K$. pneumoniae), while negative result indicated CKP (classic $K$. pneumoniae). Identification of E. coli, Klebsiella and Salmonella isolates was made morphologically and microscopically according to Cruickshank et al. (1975), and biochemically according to Kreig and Holt (1984).

For isolation and identification of Proteus, pre-enrichment of samples was made by inoculation into RappaportVassiliadis broth (Lab M), incubation at $41.5^{\circ} \mathrm{C}$ for $24 \mathrm{~h}$, then plating on XLD (Xylose Lysine Deoxycholate) agar (HiMedia), and incubation at $37^{\circ} \mathrm{C}$ for $24 \mathrm{~h}$. For isolation and 
identification of Shigella, samples were enriched in Sodium bi-selenite broth (HiMedia) according to Morris (1984) at $37^{\circ} \mathrm{C}$ for $24 \mathrm{~h}$, then plating of isolates on XLD (Xylose Lysine Deoxycholate) agar (Hi-Media) at $37^{\circ} \mathrm{C}$ for $24 \mathrm{~h}$. Streaking of inoculum was made on S-S agar (Lab M) for differentiation between Salmonella and Shigella. Identification of isolates was made morphologically and

\subsection{Isolation and}

identification of $C$. perfringens

Enrichment was made by inoculation of samples in BHI (brain heart infusion) broth (Oxoid), then anaerobic incubation in an anaerobic jar at $37^{\circ} \mathrm{C}$ for $24 \mathrm{~h}$. Enriched samples were streaked on SPS (sulphite polymixin sulphadiazine) agar plates (Hi-Media) and incubating anaerobically. Staining of suspected colonies was done with Gram's stain and subculturing on BHI (brain heart infusion) agar plates until obtaining pure culture. Biochemical tests were done as the methods defined by Merchant and Packer (1967), OIE (2000) and Calnek et al. (1997). The pure colonies suspected to be $C$. perfringens were streaked on 5\% sheep blood agar (Hi-Media) and egg yolk agar (Hi-Media) plates and anaerobically incubated at $37^{\circ} \mathrm{C}$ for $24 \mathrm{hr}$. The colonies biochemically according to Kreig and Holt (1984).

2.2. Is olation and identification of Pseudomonas aeruginosa

Inoculation of fecal swabs was made into buffered peptone water, incubation at $37^{\circ} \mathrm{C}$ for $24 \mathrm{~h}$, then streaking of inoculum on Cetrimide agar (Eur. Pharm). Biochemical Identification was made using biochemical tests according to Quinn et al. (2011) and Carter and Wise (2004).

producing double zone of hemolysis on blood agar and forming opalescence zone around the colonies on egg yolk agar; were identified as $C$. perfringens.

\section{Se rological identification}

3.1. $E$. coli and Salmonella is olates

Serological identification of $E$. coli isolates was done according to Kok et al. (1996) using rapid diagnostic E. coli antisera sets (DENKA SEIKEN Co., Japan) for diagnosis of the Enteropathogenic types. Serological identification of Salmonella isolates was made using Salmonella antiserum (DENKA SEIKEN Co., Japan) according to Kauffman - White scheme (Kauffman, 1974) for the determination of $(\mathrm{O})$ somatic and $(\mathrm{H})$ flagellar antigens.

\subsection{Klebsiella isolates}

Quellung test "Neufeld reaction" was used for serological identification of capsular antigen 
according to Edmondson and Cooke (1979). The used kit was purchased from (Statens Serum Institute, Copenhagen, Denmark). Quellung test was carried out according to the producer instructions. The antigen-antibody reactions are observed microscopically. A positive quellung reaction is the result of the binding of the capsular polysaccharide with type specific antibody contained in the typing antiserum.

\section{Antimicrobial sensitivity test} Some E. coli and Salmonella isolates were tested using 11 antimicrobial discs (Oxoid) involving amoxicillin/c lavulanic acid $(20 / 10 \mu \mathrm{g}), \quad$ ampicillin/sulbactam (10/10 $\mu \mathrm{g})$, cephalexin $(30 \mu \mathrm{g})$, ceftriaxone $(30 \mu \mathrm{g})$, cefotaxime $(30 \mu \mathrm{g})$, gentamicin $(10 \mu \mathrm{g})$, tetracycline $(30 \mu \mathrm{g})$, chloramphenicol $(30 \mu \mathrm{g})$, ciprofloxac in $(5 \mu \mathrm{g})$, trimethoprim/sulfame thoxaz ole $(1.25 / 23.75 \mu \mathrm{g}) \quad$ and erythromycin $(15 \mu \mathrm{g})$.

Antimicrobial sensitivity test was done using disk diffusion method and interpretation of the results was done according to Clinical and Laboratory Standards Institute guidelines (2015).

\section{Expe rimental infection}

5.1. Preparation of animals before the experiment:

Two kittens were used for experimental salmonellosis and two kittens were used as control. Two kittens were used for experimental E. coli infection and two kittens were used as control. Two puppies were used for experimental salmonellos is and two puppies were used as control. All animals were treated for external and internal parasites.

\section{2. \\ Experimental}

\section{Salmonellos is in dogs and cats}

It was made using the previously isolated and serologically identified $S$. Typhimurium (group B, (O) antigen: 1,4,5,12; (H) antigen: i: 1,2 ), and $S$. Heidelberg from dog during this study. Refreshment of the preserved strain was made by inoculating into BPW (Buffered Peptone Water), incubating at $37^{\circ} \mathrm{C}$ at $24 \mathrm{hr}$, then inoculating into Rappaport-Vassiliadis Broth and incubating at $41.5^{\circ} \mathrm{C}$ at 24 $\mathrm{hr}$, and then streaking onto the Xylose Lysine Deoxycholate (XLD) agar and incubating at $37^{\circ} \mathrm{C}$ for $24 \mathrm{hr}$. Serial dilution of the bacteria was made to obtain $5 \times 10^{8} \mathrm{CFU}$ of $S$. Typhimurium. Oral administration of $20 \mathrm{ml}$ of $5 \times 10^{8} \mathrm{CFU}$ of $S$. Typhimurium according to Stone et al. (1995) to the 2 puppies designated as CES1 and CES2 (Canine Experimental Salmonellosis 1 and 2), followed by $20 \mathrm{ml}$ of $5 \times 10^{8}$ CFU $S$. Heidelberg. Oral administration of $10 \mathrm{ml}$ of $5 \times 10^{8}$ CFU of $S$. Typhimurium only to the 2 kittens designated as FES1 
and FES2 (Feline Experimental Salmonellosis 1 and 2) according to Timoney et al. (1978).

5.3. Experimental $E$. coli infection in cats

It was made using the previously isolated and serologic ally identified $E$. coli (EPEC O55:H7) from dog during this study. Refreshment of the previously preserved strain was made by inoculating into BPW (Buffered Peptone Water), incubating at $37^{\circ} \mathrm{C}$ at $24 \mathrm{hr}$, then inoculating onto MacConkey's agar and incubating at $37^{\circ} \mathrm{C}$ for $24 \mathrm{hr}$. Serial dilution of the bacteria was made to obtain $10^{8}$ CFU. Oral administration of 10 $\mathrm{ml}$ of $10^{8} \mathrm{CFU}$ of $E$. coli was made to the 2 kittens designated as FEEC1 and FEEC2 (Feline Experimental E. coli 1 and 2) according to Watson et al. (2019).

5.4. Observation of animals during the experiment

Daily observation of vital signs for animals during the experiment.

\subsection{Euthanasia at the end of} the experiment

Euthanasia was made for FEEC1, FEEC2, CES1 and CES2. Sedation was made for cats with Xylazine hydrochloride and Atropine sulphate, followed by overdose of Ketamine Hydrochloride 5\%. Sedation was made for dogs with Xylazine hydrochloride and Atropine sulphate, followed by
Intra-cardiac injection of Deltamethrin.

\subsection{Necropsy}

All cases were subjected to necropsy immediately after death for naturally infected cases and the cases died from infection (FES1) and (FES2), and after euthanasia for other experimentally infected cases (FEEC1), (FEEC2), (CES1) and (CES2). All samples were taken under aseptic conditions using sterile instruments.

\section{6. \\ examination}

Specimens from small intestine, colon and liver were obtained from each animal and fixed in $10 \%$ neutral buffer formalin. Then sampled tissues were washed in water, embedded in paraffin (Luna, 1968), sectioned by a thickness of $5 \mu \mathrm{m}$, then subjected to staining with hematoxylin and eosin. Microscopic examination was performed for each tissue (Watson et al., 2017).

\section{Results}

The total identified bacterial isolates were 104 from the total 202 examined samples, as shown in Table (1). The identified isolates were $E$. coli (46; $44.23 \%)$, P. vulgaris $(12 ; 11.53)$, $P$. mirabilis $(10 ; 9.62 \%), K$. pneumoniae $(8 ; 7.69 \%), K$. oxytoca $(1 ; 0.96 \%), \quad C$. perfringens $(5 ; 4.80 \%), \quad S$. Typhimurium (1; 0.96\%), $S$. 
Infantis $\quad(1 ; \quad 0.96 \%), \quad S$. Heidelberg $\quad(1 ; \quad 0.96 \%)$, Citrobacter freundii $(1 ; 0.96 \%)$, C. diversus (1;0.96\%), Serratia liquefaciens $(1 ; 0.96 \%), \quad S$. dysenteriae (2;1.92\%), Shigella flexneri $\quad(1 ; \quad 0.96 \%)$, Enterobacter aerogenes (2; $1.92 \%)$, Enterobacter cloacae (2; $1.92 \%)$, Providencia rettgeri (2; 1.92\%), Hafnia species (1; $0.96 \%)$, Pseudomonas aeruginosa $(4 ; 3.84 \%), \quad C$. bifermentans $(1 ; 0.96 \%)$ and $C$. putrefaciens $(1 ; 0.96 \%)$. Twenty-six E. coli isolates were identified serologically, E. coli serotypes represents EHEC (12/26; $46.15 \%)$, EPEC (9/26; $34.62 \%)$, ETEC $(4 / 26 ; 15.38 \%)$ and EIEC $(1 / 26 ; 3.85 \%)$, as shown in Table (4). Seven $K$. pneumoniae were identified serologically; involving 4 isolates carried $\mathrm{K} 1$ and 2 isolate $\mathrm{s}$ carried K2, as shown in Table (3). By string test, $4 K$. pneumoniae were identified as Hypermucoviscous $K$. pneumoniae (HVKP) and 3 isolates were identified as Classic K. pneumoniae (CKP). Antimicrobial sensitivity test revealed that canine E. coli isolates were resistant to Amoxicillin/Clavulanic acid (66.67\%), Cephalexin (66.67\%), Ceftriaxone $\quad(66.67 \%)$, Cefotaxime (33.33\%), Trimethoprim/sulphamethoxazo le $(66.67 \%)$, Tetracycline $(100 \%)$ and Erythromycin
(100\%), while feline E. coli isolates had moderate resistance (50\%) to Amoxicillin/Clavula nic acid,

Trimethoprim/sulphamethoxazo le, and Tetracycline. Salmonella isolates from dogs were resistant to Amoxicillin/Clavulanic acid and Cephalexin by a percentage of $100 \%$. Salmonella isolates from dogs were resistant to Trimethoprim/sulphamethoxazo le, Tetracycline and Erythromycin by a percentage of $66.67 \%$. P. mirabilis isolate was resistant Amoxicillin/Clavulanic acid, Cephalexin, Cefotaxime, Erythromycin and Chloramphenicol. $K$. pneumoniae isolate was resistant to Erythromycin. These results were illustrated in Table (5).

Serological identification of Salmonella, K. Pneumoniae and $E$. coli isolates was illustrated in Table (2), (3) and (4), respectively. Necropsy of Experimental canine salmonellosis (CES1) showed enlarged cecum, severe congestion of intestinal blood vessels, hemorrhagic inflammation of intestine and several necrotic foci in the small intestine (jejunum). Histopathological examination of CES1 small intestine (jejunum) showed coagulative necrosis of the tips of villi along with sloughing of some epithelial cells in the lumen, 
moderate focal leukocytic of villi along with massive infiltration in the submucosa. leukocytic infiltrations. FES1 CES1 colon showed mucinous liver showing multifocal degeneration and coagulative necrosis, congestion of blood necrosis of the tips of villi. CES1 vessels and hyperplasia of bile Liver showed diffuse vacuolar degeneration, mild congestion of central veins and portal blood vessels, and mild fibrosis . Results were illustrated in Figure (1).

Necropsy of Feline ducts, as shown in Figure (2). Necropsy of Feline Experimental E. coli infection (FEEC1) revealed congestion of intestinal blood vessels and megacolon. Histopathological examination of FEEC1 small Experimental salmonellos is (FES1) revealed congestion of liver and intestinal blood vessels, hemorrhagic enteritis of intestine, enlarged mesenteric lymph nodes and pericardial edema. Histopathological examination of FES1 small intestine (jejunum) showed coagulative necrosis of the tips of villi. FES1 colon showed degeneration, necrosis of the tips intestine showed ulceration and discontinuation of intestinal mucosa with degeneration and necrosis. FEEC1 colon showed congested blood vessels and vacuolation of epithelial cells lining the villi. FEEC1 liver showed congestion of blood vessels and fibrosis around the hepatic areas, as shown in Figure (3). 
Table (1): Number and percentage of bacterial isolates from the examined dogs and cats:

\begin{tabular}{|l|c|c|c|c|}
\hline \multirow{2}{*}{ Bacterial Is olate } & Total & Percentage & \multicolumn{2}{c|}{ Animal species } \\
\cline { 4 - 6 } & Number & $(\%)$ & Cats & Dogs \\
\hline E. coli & 46 & 44.23 & 18 & 28 \\
\hline S. Typhimurium & 1 & 0.96 & 0 & 1 \\
\hline S. Infantis & 1 & 0.96 & 0 & 1 \\
\hline S. Heidelberg & 1 & 0.96 & 0 & 1 \\
\hline Proteus mirabilis & 10 & 9.62 & 2 & 8 \\
\hline Proteus vulgaris & 12 & 11.53 & 2 & 10 \\
\hline Klebsiella pneumoniae & 8 & 7.69 & 2 & 6 \\
\hline Klebsiella oxytoca & 1 & 0.96 & 0 & 1 \\
\hline Shigelladysenteriae & 2 & 1.92 & 2 & 0 \\
\hline Shigellaflexneri & 1 & 0.96 & 0 & 1 \\
\hline Citrobacterfreundii & 1 & 0.96 & 0 & 1 \\
\hline Citrobacter diversus & 1 & 0.96 & 0 & 1 \\
\hline Serratialiquefaciens & 1 & 0.96 & 0 & 1 \\
\hline Enterobactercloacae & 2 & 1.92 & 0 & 2 \\
\hline Enterobacteraerogenes & 2 & 1.92 & 1 & 1 \\
\hline Providenciarettgeri & 2 & 1.92 & 0 & 2 \\
\hline Hafnia species & 1 & 0.96 & 1 & 0 \\
\hline C. perfringens & 5 & 4.80 & 0 & 5 \\
\hline C. putrefaciens & 1 & 0.96 & 0 & 1 \\
\hline C. bifermentans & 104 & $51.48 \%$ & 30 & 74 \\
\hline Pseudomonas aeruginosa & & 0.96 & 0 & 1 \\
\hline TotalNumber of isolates & & 3.84 & 2 & 2 \\
\hline
\end{tabular}

Table (2): Salmonella serotypes from the examined dogs and cats:

\begin{tabular}{|c|c|c|c|c|c|}
\hline \multirow{2}{*}{$\begin{array}{c}\text { Serial } \\
\text { No. }\end{array}$} & $\begin{array}{c}\text { Key } \\
\text { No. }\end{array}$ & Identified strain & Group & \multicolumn{2}{|c|}{$\begin{array}{c}\text { Antigenic } \\
\text { structure }\end{array}$} \\
\cline { 5 - 6 } & & & $\mathbf{O}$ & $\mathbf{H}$ \\
\hline 1 & D24 & $\begin{array}{c}\text { Salmonella } \\
\text { Typhimurium }\end{array}$ & $\mathrm{B}$ & $1,4,5,12$ & i: 1,2 \\
\hline 2 & D25 & Salmonella Infantis & C1 & $6,7,14$ & r: 1,5 \\
\hline 3 & D35 & $\begin{array}{c}\text { Salmonella } \\
\text { Heidelberg }\end{array}$ & $\mathrm{B}$ & $1,4,5,12$ & r: 1,2 \\
\hline
\end{tabular}


Table (3): Serotypes of K. pneumoniae:

\begin{tabular}{|c|c|c|c|c|c|}
\hline $\begin{array}{c}\text { Serial } \\
\text { No }\end{array}$ & $\begin{array}{c}\text { Key } \\
\text { No }\end{array}$ & $\begin{array}{c}\text { Identified } \\
\text { bacterium }\end{array}$ & Biotyping & $\begin{array}{c}\text { String } \\
\text { test }\end{array}$ & Serodiagnosis \\
\hline 1 & $\mathrm{C} 46$ & $\begin{array}{c}\text { Klebsiella } \\
\text { pneumoniae }\end{array}$ & $\mathrm{B} 1$ & $\mathrm{HVKP}$ & $\mathrm{K} 1$ \\
\hline 2 & $\mathrm{C} 59$ & $\begin{array}{c}\text { Klebsiella } \\
\text { pneumoniae }\end{array}$ & $\mathrm{B} 1$ & $\mathrm{CKP}$ & Untypable \\
\hline 3 & $\mathrm{D} 90$ & $\begin{array}{c}\text { Klebsiella } \\
\text { pneumoniae }\end{array}$ & $\mathrm{B} 1$ & $\mathrm{HVKP}$ & $\mathrm{K} 1$ \\
\hline 4 & $\mathrm{D} 103$ & $\begin{array}{c}\text { Klebsiella } \\
\text { pneumoniae }\end{array}$ & $\mathrm{B} 1$ & $\mathrm{HVKP}$ & $\mathrm{K} 2$ \\
\hline 5 & $\mathrm{D} 122$ & $\begin{array}{c}\text { Klebsiella } \\
\text { pneumoniae }\end{array}$ & $\mathrm{B} 4$ & $\mathrm{CKP}$ & $\mathrm{K} 1$ \\
\hline 6 & $\mathrm{D} 125$ & $\begin{array}{c}\text { Klebsiella } \\
\text { pneumoniae }\end{array}$ & $\mathrm{B} 1$ & $\mathrm{HVKP}$ & $\mathrm{K} 1$ \\
\hline 7 & $\mathrm{D} 133$ & $\begin{array}{c}\text { Klebsiella } \\
\text { pneumoniae }\end{array}$ & $\mathrm{B} 3$ & $\mathrm{CKP}$ & $\mathrm{K} 2$ \\
\hline
\end{tabular}

*CKP: Classic Klebsiella pneumoniae* HVKP: Hypermucoviscous K. pneumoniae

Table (4): The identified $E$. coli serotypes from the examined dogs and cats:

\begin{tabular}{|c|c|c|c|c|c|c|c|c|}
\hline Type & \multirow{2}{*}{\multicolumn{2}{|c|}{$\begin{array}{c}\text { EHEC } \\
\text { NO } \\
\%\end{array}$}} & \multicolumn{2}{|c|}{ EPEC } & \multicolumn{2}{|c|}{ ETEC } & \multicolumn{2}{|c|}{ EIEC } \\
\hline \multirow{2}{*}{ Prevalence } & & & $\mathrm{NO}$ & $\%$ & & & & \\
\hline & \multicolumn{2}{|c|}{$\begin{array}{l}12 / 26 \\
46.15\end{array}$} & \multicolumn{2}{|c|}{$\begin{array}{c}9 / 26 \\
34.62\end{array}$} & \multicolumn{2}{|c|}{$4 / 26$} & \multicolumn{2}{|c|}{$1 / 26$} \\
\hline Serotypes & \multicolumn{2}{|c|}{ 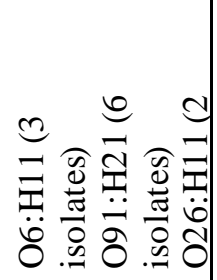 } & \multicolumn{2}{|c|}{ 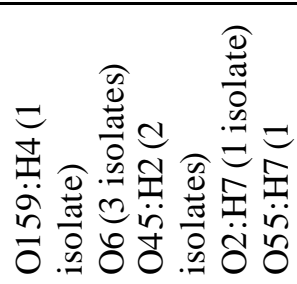 } & \multicolumn{2}{|c|}{ 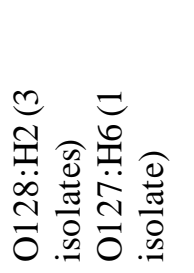 } & \multicolumn{2}{|c|}{$\begin{array}{l}0 \\
\frac{0}{0} \\
0 \\
0 \\
0 \\
0 \\
0 \\
0 \\
0\end{array}$} \\
\hline Species & Dogs & Cats & Dogs & Cats & Dogs & Cats & Dogs & Cats \\
\hline NO & 9 & 3 & 7 & 2 & 1 & 3 & 0 & 1 \\
\hline$\%$ & 75 & 25 & 77.78 & 22.22 & 25 & 75 & 0 & 100 \\
\hline
\end{tabular}


Table (5): Prevalence of some resistant bacterial isolates from the examined dogs and cats:

\begin{tabular}{|c|c|c|c|c|c|c|c|}
\hline \multirow{4}{*}{ Apecies } & \multicolumn{7}{|c|}{ Resistant bacterial isolates number $(\%)$} \\
\hline & \multirow{2}{*}{\multicolumn{2}{|c|}{$\begin{array}{c}\text { E. coli } \\
(\mathbf{n}=5)\end{array}$}} & \multicolumn{3}{|c|}{ Salmonella isolates $(n=3)$} & \multirow{3}{*}{$\begin{array}{l}\text { Proteus } \\
\text { mirabilis } \\
(\mathrm{n}=1)\end{array}$} & \multirow{3}{*}{$\begin{array}{c}\text { Klebsiella } \\
\text { pneumoniae } \\
(\mathrm{n}=1)\end{array}$} \\
\hline & & & \multirow{2}{*}{$\underset{\substack{(n=1) \\
\text { Typhimurium }}}{S .}$} & \multirow{2}{*}{$\begin{array}{c}S . \\
\text { Inf antis } \\
(n=1)\end{array}$} & \multirow{2}{*}{$\begin{array}{c}S . \\
\text { Heidelberg } \\
(\mathbf{n}=1)\end{array}$} & & \\
\hline & $\begin{array}{l}\text { Dogs } \\
(\mathrm{n}=\mathbf{3})\end{array}$ & $\begin{array}{l}\text { Cats } \\
(n=2)\end{array}$ & & & & & \\
\hline $\begin{array}{c}\text { Amoxicillin/ } \\
\text { Clavulanic acid }\end{array}$ & $2(66.67)$ & $1(50)$ & \multicolumn{3}{|c|}{$3(100)$} & $1(100)$ & $\mathbf{0}$ \\
\hline $\begin{array}{l}\text { Ampicillin/ } \\
\text { Sulbactam }\end{array}$ & $\mathbf{0}$ & $\mathbf{0}$ & \multicolumn{3}{|c|}{$\mathbf{0}$} & $\mathbf{0}$ & $\mathbf{0}$ \\
\hline Cephalexin & $2(66.6)$ & $\mathbf{0}$ & \multicolumn{3}{|c|}{ 3(100) } & $1(100)$ & $\mathbf{0}$ \\
\hline Cef triaxone & $2(66.6)$ & $\mathbf{0}$ & \multicolumn{3}{|c|}{$\mathbf{0}$} & $\mathbf{0}$ & $\mathbf{0}$ \\
\hline Cefotaxime & $1(33.3)$ & $\mathbf{0}$ & \multicolumn{3}{|c|}{$\mathbf{0}$} & $1(100)$ & $\mathbf{0}$ \\
\hline Ciprofloxacin & $\mathbf{0}$ & $\mathbf{0}$ & \multicolumn{3}{|c|}{$\mathbf{0}$} & $\mathbf{0}$ & $\mathbf{0}$ \\
\hline Gentamicin & $\mathbf{0}$ & $\mathbf{0}$ & \multicolumn{3}{|c|}{$\mathbf{0}$} & $\mathbf{0}$ & $\mathbf{0}$ \\
\hline $\begin{array}{c}\text { Trimethoprim/ } \\
\text { Sulf amethoxaze }\end{array}$ & $2(66.6)$ & $1(50)$ & \multicolumn{3}{|c|}{$2(66.67)$} & $\mathbf{0}$ & $\mathbf{0}$ \\
\hline Tetracycline & 3(100) & $1(50)$ & \multicolumn{3}{|c|}{$2(66.67)$} & $\mathbf{0}$ & $\mathbf{0}$ \\
\hline Erythromycin & $3(100)$ & $\mathbf{0}$ & \multicolumn{3}{|c|}{$2(66.67)$} & $1(100)$ & $1(100)$ \\
\hline Chloramphenid & $\mathbf{0}$ & $\mathbf{0}$ & \multicolumn{3}{|c|}{ 0 } & $1(100)$ & $\mathbf{0}$ \\
\hline
\end{tabular}

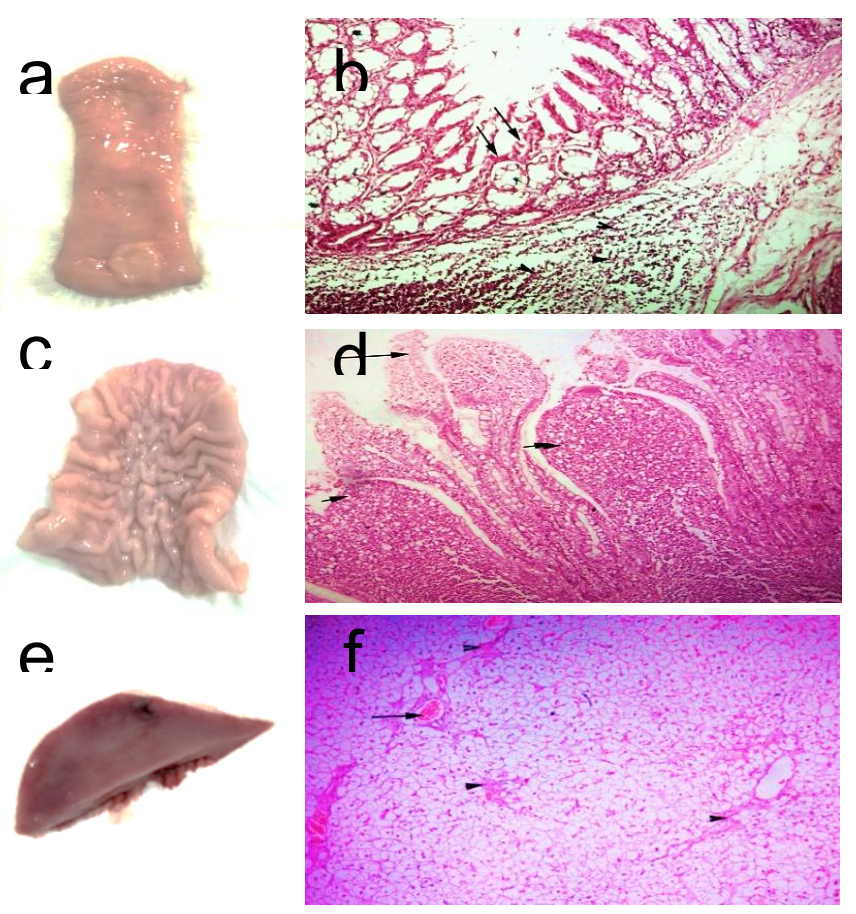

Figure (1): Macroscopic and microscopic picture of Canine Experimental Salmonellosis 1 (CES1) 
(a) Jejunum: showed necrotic foci in jejunum (c) Colon: severe inflammation (e) Liver: showed congestion

(b) CES1 jejunum: showing coagulative necrosis of the tips of villi (arrows) along with sloughing of some epithelial cells in the lumen, moderate focal leukocytic infiltration in the submucosa (arrow heads). $\mathrm{H} \& \mathrm{E}, \mathrm{X} 200$.

(d) CES1 colon: showing mucinous degeneration and coagulative necrosis of the tips of villi (arrows) along with sloughing of some epithelial cells in the lumen. H\&E, X 200.

(f) CES1 liver: showing diffuse vacuolar degeneration, mild congestion of central veins and portal blood vessels (arrows), and mild fibrosis (arrow heads). H\&E, X 200.

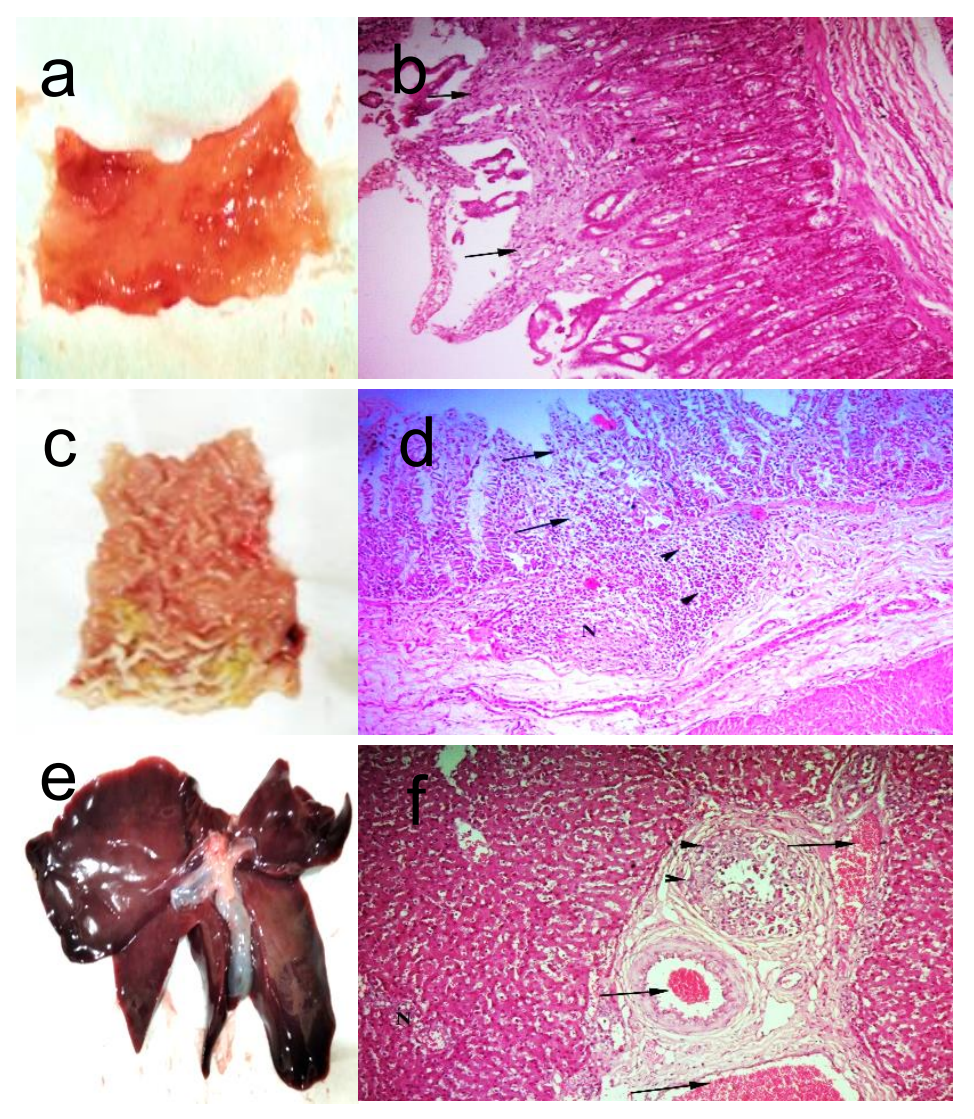

Figure (2): Macroscopic and microscopic picture of Feline Experimental Salmonellosis 1 (FES1)

(a) Je junum: showing hemorrhagic inflammation (c) Colon: showing hemorrhagic inflammation (e) Liver and gall bladder: showing congestion of liver 
(b) FES1 jejunum: showing coagulative necrosis of the tips of villi (arrows) along with sloughing of some epithelial cells in the lumen. $\mathrm{H} \& \mathrm{E}, \mathrm{X} 200$.

(d) FES1 colon: showing degeneration (arrows), necrosis $(\mathrm{N})$ of the tips of villi along with massive leukocytic infiltrations (arrow heads). $\mathrm{H} \& \mathrm{E}, \mathrm{X} 200$.

(f) FES1 liver: showing multifocal necrosis $(\mathrm{N})$, congestion of blood vessels (arrows) and hyperplasia of bile ducts (arrow heads). H\&E, X 200.
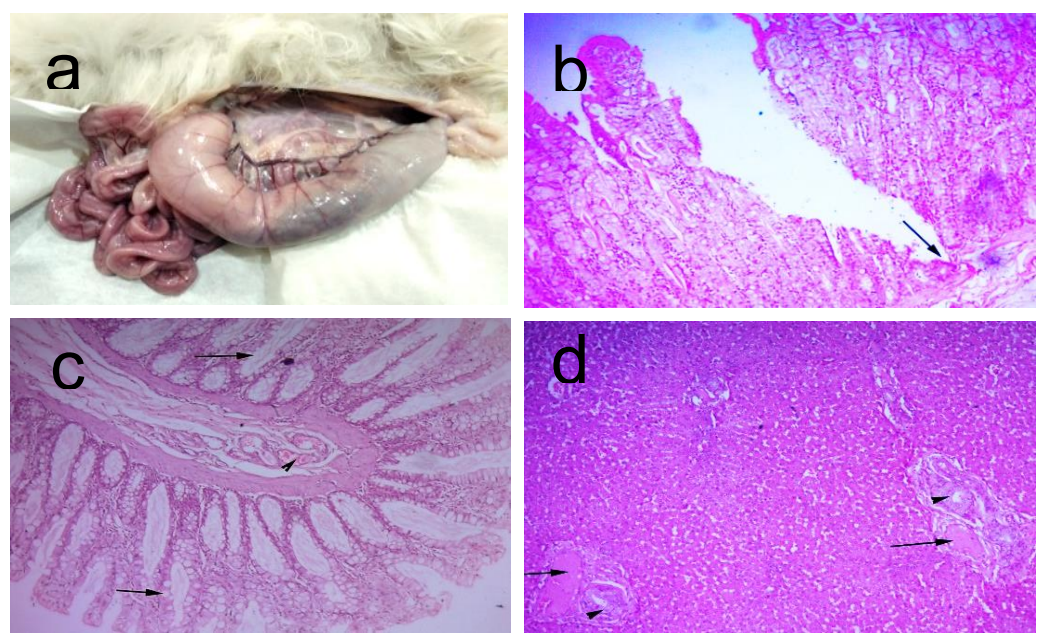

Figure (3): Macroscopic and microscopic picture of Feline Experimental E. coli infection 1 (FEEC1)

(a) Intes tine of FEEC1: showing congestion of intestinal blood vessels and megacolon.

(b) FEEC1 jejunum: showing ulceration and discontinuation of intestinal mucosa (arrow) along with degeneration and necrosis. H\&E, X 200.

(c) FEEC1 colon: showing congested blood vessels (arrow head), vacuolation of epithelial cells lining the villi (arrows). H\&E, X 200.

(d) FEEC1 liver: showing multiple congestion of blood vessels (arrows), hyperplasia of bile ducts (arrow heads) and fibrosis around the hepatic areas. H\&E, X 200.

\section{Discussion}

Hemorrhagic gastroenteritis (HGE) is a disease typically affects small breed dogs, young to middle-age, although dogs of any breed or age can be affected.
The disease characterized by a per acute onset of clinical signs that can develop rapidly to death without proper treatment (Trotman, 2014). At necropsy, the main intestinal lesions of 
HGE in dogs were exhibited superficial hemorrhagic necrosis of the mucosa (Cave et al., 2002; and Unterer et al., 2014). The most common bacterial species isolated from dogs with Acute Hemorrhagic

Diarrhea

Syndrome (AHDS) was E. coli that is considered an enteropathogen. Gastrointestinal diseases in dogs specially in young puppies are attributed to E. coli, notably, enteropathogenic (EPEC), enterohemorrhagic (EHEC), and enterotoxigenic (ETEC) strains (Marks and Kather, 2003). In this study, the most prevalent isolate was $E$. coli $(46 ; 44.23 \%)$. From the 26 isolates subjected to serological examination, the percentages of isolation of EHEC, EPEC and ETEC strains were $12 / 26 \quad(46.15 \%), \quad 9 / 26$ (34.62\%), and 4/26 (15.38\%), respectively. The previous results were in agreement with that recorded by Marks and Kather (2003); who said that the three pathotypes enterohemorrhagic E. coli (EHEC), enterotoxigenic E. coli (ETEC), and enteropathogenic E. coli (EPEC) had been studied in dogs. In the present study, the three Salmonella isolates were serotyped as Salmonella Typhimurium, $S$. Heidelberg and $S$. Infantis, while in a study performed by Ojo and Adetosoye, (2009), all the Salmonella isolates were serotyped as $S$. Typhimurium. In this study, the prevalence of $K$. pneumoniae isolates was (8; $7.69 \%)$ and $K$. oxytoca (1; $0.96 \%)$. In a report documented by Roberts et al. (2000); a severe $K$. pneumoniae enteritis outbreak occurred in Bordeaux mastiffs, producing septicemia and death. The symptoms began with vomiting and diarrhea. Seven adult dogs had symptoms, and 4 died. Vomiting and bloody or watery diarrhea were present in all affected animals. Serological identification of $7 \mathrm{~K}$. pneumoniae isolates showed that 4 isolates carried $\mathrm{K} 2$ and 2 isolates carried $\mathrm{K} 2$ indicating their virulence; these results were in agreement with that reported by Holt et al. (2015) and Effah et al. (2020); that the Hypermucoviscous $K$. pneumoniae (HMKP) or Hypervirulent $K$. pneumoniae (hyKp) is known to carry virulence factors including capsular types K1, K2 and K20. $E$. coli isolates from dogs were resistant

Amoxicillin/Clavulanic acid by a percentage of $(66.67 \%)$, Cephalexin $\quad(66.67 \%)$, Ceftriaxone $(66.67 \%)$,

Trimethoprim/sulphamethoxazo le $(66.67 \%)$, Tetracycline $(100 \%)$ and Erythromycin $(100 \%)$. These results were not similar to that reported in a study performed by Habib et al. (2016); who recorded that $E$. coli 
isolates had high to moderate resistance to tetracycline $(54.33 \%)$ and ceftriaxone (44.88\%). Similar E. coli resistance pattern has been reported previously (Minton et al., 1983).

Also, feline E. coli isolates had moderate resistance to Amoxicillin/clavulanic acid (50\%),

trimethoprim/sulphametoxazole $(50 \%)$, and tetracycline (50\%). These results were similar to that reported by Habib et al. (2016). Also, similar pattern of $E$. coli resistance had been reported previously by (Minton et al., 1983). Monaghan et al. (1981); reported moderate to high level of antibiotic resistance to different antibiotics in E. coli. Also, Pedersen et al. (2007); reported high level of resistance to tetracycline and sulphonamides in E. coli.

In the current study, the antimicrobial sensitivity pattern of the three Salmonella isolates was determined. High susceptibility rate was demonstrated to Ampicillin/Sulbactam (100\%), Ceftriaxone (100\%), Cefotaxime (100\%), Ciprofloxacin (100\%), Gentamicin (100\%) and Chloramphenicol (100\%). This result was nearly similar to that reported by Ojo and Adetosoye, (2009); where they recorded a high susceptibility to Ciprofloxacin (100\%) and
Chloramphenicol

$(89.2 \%)$. Resistance was shown to Tetracycline $(66 \%)$, Erythromycin $(66 \%)$, Trimethoprim/sulphamethoxazo le $(66 \%)$, Cephalexin $(100 \%)$ and Amoxicillin/Clavulanic acid (100\%). Ojo and Adetosoye, (2009); reported that resistance was to Tetracycline $(70.6 \%)$ and Amoxicillin (35.3\%).

In the present study, in case of feline experimental salmonellosis, FES1 liver showing multifocal necrosis, congestion of blood vessels and hyperplasia of bile ducts, these results were similar to that reported by Stiver et al. (2003); who found that histopathological examination revealed necrotizing hepatitis with random, multifocal small areas of hepatic cells necrosis and associated neutrophilic and histiocytic inflammation. Also, it showed subacute to chronic enteritis with lymphoplasmacytic, histiocytic, and neutrophilic infiltrates in the lamina propria. Clinical Salmonellos is is rare in adult dogs despite presence of some serotypes in healthy animals, but the disease is more dangerous in young animals and animals exposed to stress condition (Kallo and Hasso, 2001). In the present study, this was very clear as cats and dogs infected by experimental salmonellos is showed signs of infection when 
immunosuppression occurred as a result of fungal infection. In the present study, in case of canine experimental salmonellos is, CES1 liver showing diffuse vacuolar degeneration, these results were similar to that recorded in a study performed by Giuliano et al. (2015), in a dog that the histopathology of the liver showed acute hepatic necrosis. Identified areas of diffuse liver necrosis were defined, with only some normal hepatic cells exist in the portal areas. Inflammatory infiltrates of lymphocytes, neutrophils, and plasma cells were identified with areas of multifocal cholestasis. Areas of multifocal hemorrhage were also present. In the present study, the re-isolated strain from fecal sample of canine experimental infection was $S$. Typhimurium group B of serotype $1,4,5,12$, i: 1,2 . This result was in agreement with that documented in a study performed by Giuliano et al. (2015); where the microbiological examination detected the isolation of

\section{Conclusion}

From the previous results of the study, it can be concluded that the prognosis of HGI is excellent with proper and rapid treatment. Clinical salmonellosis is rare in cats. E. coli isolates from the examined dogs and cats belonged to EHEC, ETEC,
Salmonella enterica of group B from the liver, while in the present study, it was isolated from the intestinal tract. Bacteria were cultured by an enrichment technique. The result reported the presence of Typhimuriumlike $S$. enterica of serotype I 4,5,12: -:1,2 (Giuliano et al., 2015). In the present study, in case of feline experimental $E$. coli infection, FEEC1 small intestine showed ulceration and discontinuation of intestinal mucosa along with degeneration and necrosis, these results were similar to that recorded in a study performed by Waston et al. (2017), where the results of histopathology of kittens, that died or euthanized due to diarrhea, revealed a significant relation between aEPEC isolates detection from kittens and lesions in the colon and small intestine. Lesions were characterized by the presence of injury in the small intestinal epithelium with presence of an inflammatory infiltrate in the small intestine and colon.

EPEC serotypes, and the most prevalent was EHEC serotypes. The MDR bacteria spread is a problem requires restriction. Histopathology of experimental salmonellosis in dogs and cats showed necrosis of the tips of the villi of the small intestine. Histopathology of experimental $E$. coli in cats showed ulceration 
of intestinal mucosa with degeneration and necrosis.

\section{Author contributions}

MEE and ME designed the study. MEE, AW and MEA collected the samples, and applied bacteriological examinations. MEE, MEA and AW performed serological identification. MEE and MEA wrote the manuscript. MEE, ME, AW, WMH and AAD applied experimental and pathological studies. All authors have read and approved the final manuscript.

\section{References}

Calnek, B.W., Bames, H.J., Beard, C.W., McDougald, L.R., Saif, Y.M.(1997): Disease of Poultry, 10th edition, lowa State University Press, Ames, lowa, USA.

Carter, G.R. and Wise, D.J. (2004): Essentials of Veterinary Bacteriology and Mycology. 6th ed. The Iowa State Press, Iowa, p125-126.

Cave N.J., Marks S.L., Kass P.H., et al. (2002): Evaluation of a routine diagnostic fecal panel for dogs with diarrhea. J Am Vet Med Assoc; 221:52-59.

Clinical and Laboratory Standards Institute guidelines (2015): Performance Standards for Antimicrobial Susceptibility Testing; Twenty-Fifth Informational Supplement. Vol.
35. Clinical and Laboratory Standards Institute, Wayne, PA, USA.

Cruickshank, R.; Duguid, J.; Marmion, B. and Swain, R.H. (1975): Medical Microbiology. 12th Ed., Edinburg, London and New York.

Edmondson, A. and Cooke E. (1979): The production of antisera to the Klebsiella capsular antigens. J. Appl. Bacteriol.; 46(3): 579-584.

Effah C.Y., Sun T., Liu S. and Wu Y. (2020): Klebsiella pneumoniae: an increasing threat to public health; Ann Clin Microbiol Antimicrob; 19:1-9.

Giuliano A., Meiring T., Grant J.A., Wats on J.P.(2015): Acute Hepatic Necrosis Caused by Salmonella enterica Serotype I4,5,12: -:1,2 in a Dog, Journal of Clinical Microbiology; 53:36743676.

Habib I., Anjum A.A., Rabbani M., Ahmad D.UM., Ali A.M., M. Nawaz M., Kamran M. and Khan M.H. (2016): Occurrence of Antimicrobial Resistant Bacteria in Dogs Suffering from Enteritis, The Journal of Animal \& Plant Sciences, 26(1), Page: 13-16, ISSN: 1018-7081.

Holt K.E., Wertheim H., Zadoks R.N., Baker S., Whitehouse C.A., Dance D., Jenney A., Connor T.R., Hsu 
L.Y., Severin J., Brisse S. (2015): Genomic analysis of diversity, population structure, virulence, and antimicrobial resistance in Klebsiella pneumoniae, an urgent threat to public health. Proc Natl Acad Sci.; 112(27): E3574-81.

Kallo O.J. and Hasso S.A. (2001): Prevalence of Salmonellae serotype in dogs and their sensitivity to antimicrobials. Iraqi. J. Vet. Sci., 14: 67-71.

Krause G., Zimmermann S. and Beutin L. (2005): Investigation of domestic animals and pets as a reservoir for intimin- (eae) gene positive Escherichia coli types. Veterinary Microbiology; 106: p.87-95.

Kreig, N. and Holt, J. (1984): Bergey's Manual of systemic bacteriology Vol.1.William and Wilkins, Baltimore, M.D.21202, USA.

Leahy A.M., Cummings K.J., Rodriguez-Rivera L.D., Rankin S.C. \& Hamer S.A. (2016): Evaluation of faecal Salmonella shedding among dogs at seven animal shelters across Texas. Zoonoses Public Health; 63:515-521.

Luna, L.G. (1968): Manual of histologic staining methods of the Armed Forces Institute of Pathology. 3rd ed. New York: McGraw-Hill.
Kauffiman,

G.

(1974):

Kauffmann white scheme. J. Acta. Path. Microbiol. Sci., 61:385.

Kok, T.; Worswich, D. and Gowans, E. (1996): Some serological techniques for microbial and viral infections. In Practical Medical Microbiology (Collee, J.; Fraser, A.; Marmion, B. and Simmons, A., eds.), 14th ed., Edinburgh, Churchill Lvingstone, UK.

Marks S.L. and Kather E.J. (2003): Bacterial associated diarrhea in the dog: a critical appraisal. Vet Clin North Am Small AnimPract; 33: 10291060.

Merchant, I.A. and Packer, R.A. (1967): Veterinary Bacteriology and Virology. Seventh edn., The Iowa University Press, Ames, Iowa, USA, pp. 286-306.

Minton, N.P., J. Marsh and T. Atkinson (1983): The R factors of multiple antibiotic resistant faecal coliforms isolated from a domestic dog. J Appl Bacteriol., 55: 445-452.

Monaghan, C., U. Tierney and E. Colleran (1981): Antibiotic resistance and R-factors in the fecal coliform flora of urban and rural dogs. Antimicrob. Agents Chemother., 19: 266-270. 
Morris, G.K. (1984): Shigella. In: Compendium of Methods for the Microbiological Examination of Foods, 2nd edition. APHA, Washington DC. pp. 343-350.

OIE (Office International Des Epizooties) (2000): Mannual of standards for diagnostics test and vaccines. OIE Guide-2.

Ojo E. O. and Adetosoye I. A. (2009):

"Salmonella

Typhimurium infection in diarrhoeic and non-diarrhoiec dogs in Ibadan, Nigeria," VeterinarskiArhiv, vol. 79(4): 371-377.

Pedersen, K., H. Jensen, K. Finster, V.F. Jensen and O.E. Heuer (2007): Occurrence of antimicrobial resistance in bacteria from diagnostic samples from dogs. J. Antimicrob. Chemother.; 60: 775- 781.

\section{Pitout}

J.D.

(2013):

Enterobacteriaceae that produce extended-spectrum betalactamases and AmpC betalactamases in the community: the tip of the iceberg? Curr Pharm Des.; 19:257-63.

Quinn, P.J., Markey, B.K., Leonard, F.C., Fitz Patrick, E.S., Fanning, S. and Hartigan, P.J. (2011): Veterinary Microbiology and Microbial Diseases. 2nd ed. Blackwell Publishing Ltd., Ames, IA., p287-290.
Roberts D.E., McClain H.M., Hansen D.S., Currin P., Howerth E.W. (2000): An outbreak of Klebsiella pneumoniae infection in dogs with severe enteritis and septicemia; J Vet Diagn Invest; 12:168-173.

Shon, A.; Bajwa, R. and Russo, T. (2013): Hypervirulent (hypermucoviscous) Klebsiella pneumoniae: A new and dangerous breed. Virulence; 4(2): 107-118.

Stiver L.S., Frazier S.K., Mauel J.M., Styer L.E. (2003): Septicemic Salmonellosis in Two Cats Fed a Raw-Meat Diet, J Am Anim Hosp Assoc; 39:538542.

Stone G.G., Oberst R.D., Hays M.P., McVey S., Galland J.C., and Curtiss R. (1995): Detection of Salmonella Typhimurium from rectal swabs of experimentally infected beagles by short cultivation and PCR-hybridization. J. Clin. Microbiol.; 33: 1292-1295.

Timoney J.F., Niebert H.C., Scott F.W. (1978): Feline salmonellosis. A nosocomial outbreak and experimental studies. Cornell Vet; 68:211219.

Trevena W.B., Hooper R.S., Wray C., Willshaw G.A., Cheasty T., Domingue G. (1996): Vero cytotoxin producing Escherichia coli 
qO157 associated with Watson E.V., Jacobb E.M., companion animals, Vet. Rec.; Bruno-Bárcenac M.J., 138-400.

Amirsultana S., Stauffera H.S.,

Trotman T.K. (2014): Gastroenteritis. In: Small Animal Critical Care Medicine. Second Edition; Chapter (117); 622-626.

Unterer S., Busch K., Leipig M., Hermanns W., Wolf G., Straubinger R.K., Mueller R.S., and Hartmann K. (2014): Endoscopically Visualized Lesions, Histologic Findings, and Bacterial Invasion in the Gastrointestinal Mucosa of Dogs with Acute Hemorrhagic Diarrhea Syndrome, J Vet Intern Med; 28:52-58.

Unterer S., Strohmeyer K., Kruse D.B., Sauter-Louis C., and Hartmann K. (2011): Treatment of Aseptic Dogs with Hemorrhagic Gastroenteritis with Amoxicillin /Clavulanic Acid: A Prospective Blinded Study, J Vet Intern Med; 25:973979. Jody Lo.V., Friasd R., Influence of the intestinal microbiota on disease susceptibility in kittens with

experimentally-induced carriage of atypical enteropathogenic Escherichia coli, Veterinary Microbiology; 231:197-206.

Watson E.V., Jacob E.M., F., Strong J.S., DebRoy C., Gookin L.J. (2017): Association of Atypical Enteropathogenic Escherichia coli with Diarrhea and Related Mortality in Kitten, Journal of Clinical Microbiology; 55:27192735.

Weese, J. S. (2011): Bacterial Dogs and Cats: Diagnosis, Therapy, and Zoonotic Potential. Veterinary Clinics of North America: Small Animal Practice, 41(2), 287-309. 


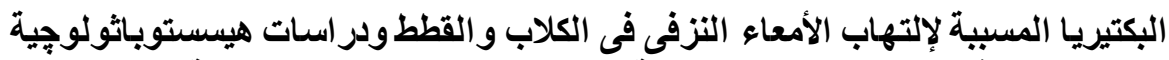

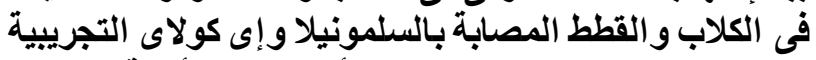

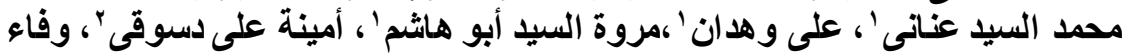

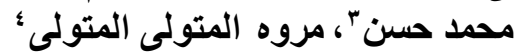

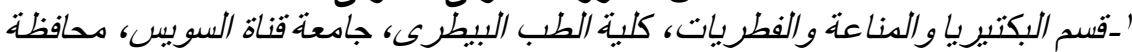

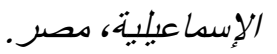

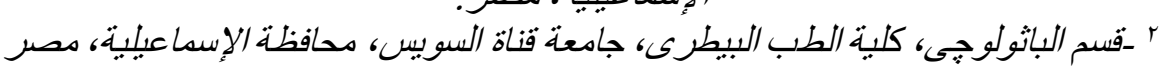

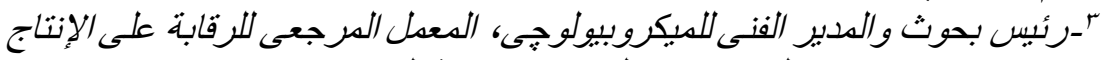

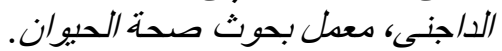
ع-إدارة الأمراض المشتركة، مديرية الطب البيطرى، دمياط، مصر.

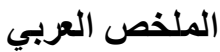

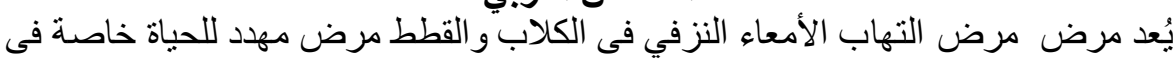

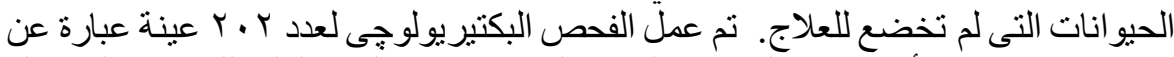

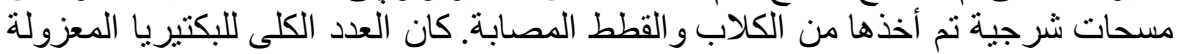

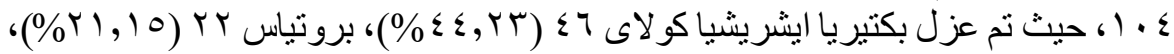

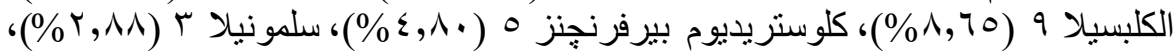

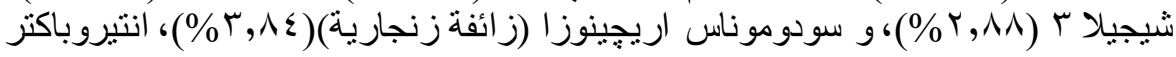

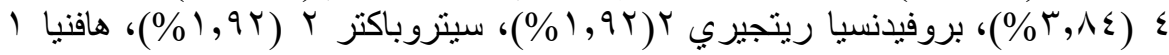

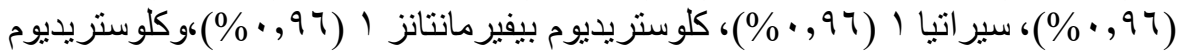

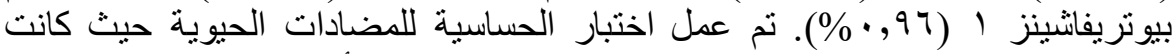

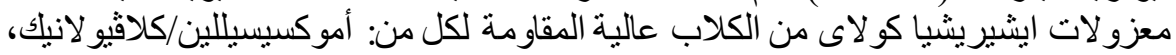

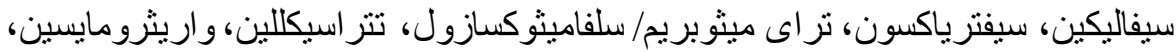

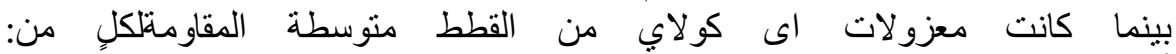

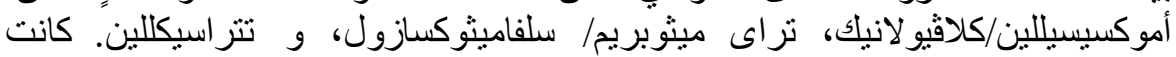

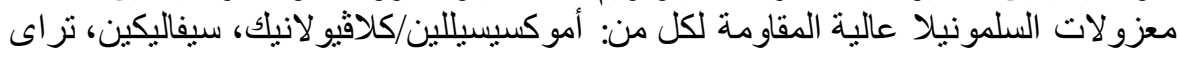

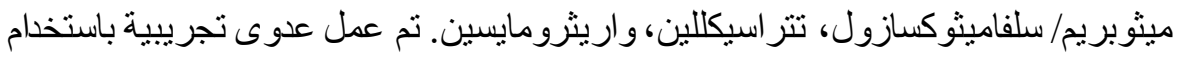

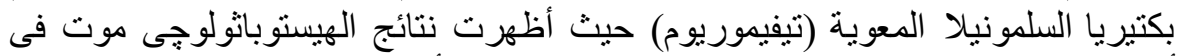

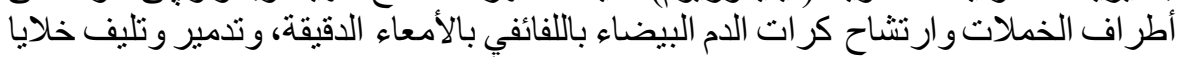

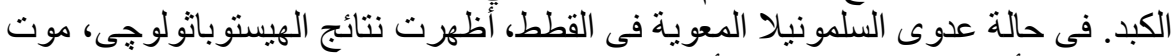

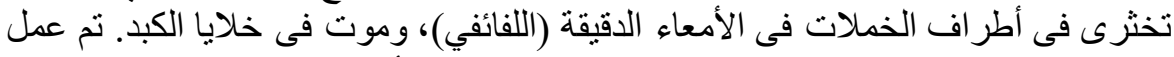

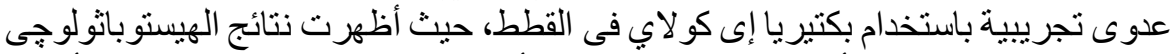

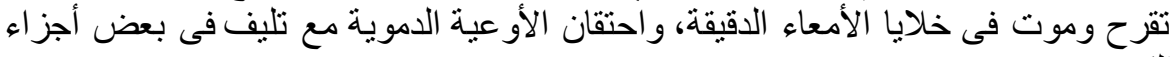
الكبد.

الكلمات المفتاحية: (التهاب الأمعاء النزفي- دراسات هيستوباتولوجيةــ عدوى تجريبيةسلمونبلا- إى كو لاى- الكلاب و القطط). 